\title{
Nietzsche, a genealogia, a história: Foucault, a genealogia, os corpos
}

\author{
Carlos Eduardo Ribeiro*
}

Resumo: Este artigo analisa as quatro primeiras partes do trabalho de Foucault Nietzsche, a genealogia, a história (1971), demonstrando que há três ênfases elaboradas sobre o procedimento genealógico. Elas são determinantes da própria práxis genealógica do pensador francês. Proponho dois momentos de análise: uma retomada e uma avaliação de aspectos da "leitura" que Foucault faz da genealogia para, a partir deste parti pris: desenvolver a consequência mais importante: ao substituir o corpo como instinto pelo sujeito como função, a genealogia foucaultiana encontra sua originalidade como genealogia de corpos históricos.

Palavras-chave: genealogia, história, corpos, origem.

* Professor da Universidade Federal do ABC (UFABC), São Bernardo do Campo, SP, Brasil. Correio eletrônico: cadufilosofia@gmail.com. 
Ribeiro, C. E.

\section{Introdução}

Pode parecer irônico que os insights pioneiros de Foucault tenham sido eles mesmos, em grande medida, estimulados por uma certa cegueira em relação à noção de "Ursprung" de Nietzsche. Mas como Paul de Man nos ensinou a todos, a cegueira e o insight estão inextricavelmente entrelaçados. ${ }^{1}$

Inúmeros comentários foram feitos sobre a marca nietzschiana no pensamento de Foucault. Esta tentativa é revisitada de tal maneira que ela carrega por trás de si uma história de como se leu tais relações de apropriação, leitura ou comentário de Foucault a respeito de Nietzsche. Uma perspectiva comum que se destaca é certamente a apropriação metodológica que faz Foucault da genealogia do pensador alemão. Encontraremos, sem esforços, uma quantidade enorme de trabalhos que se dedicam a desvendar esta frente de estudos. Minha proposta dirige-se menos a avaliar como se estabelece a genealogia para os dois pensadores, suas trocas e alterações conceituais e mais a demonstrar como Foucault, aparentemente realizando um trabalho exegético com o texto nietzschiano está, na verdade, ativando a genealogia de Nietzsche sob três ênfases específicas: como estratégia desconstrutiva, como uma luta pelo corpo, dentro de um campo de atuação de poderes.

Destas três ênfases, veremos que o corpo é o termo destacado desta ativação foucaultiana da genealogia já que ele aparecerá como o resultado pelo qual a história se realiza destituído da dimensão instintual originalmente presente em Nietzsche. Com o título do presente artigo estou, portanto, parodiando Foucault quando ele estuda a genealogia nietzschiana em Nietzsche, a genealogia, a história. ${ }^{2}$ Estou substituindo a história pelo corpo, estou dizendo

1 J. Pizer, 1990, p. 478. Livre tradução minha e revisão de Jeffry H. Ghersi a quem manifesto meu agradecimento.

2 M. Foucault, 2001, pp. 1004-1024. Por vezes, o leitor brasileiro vai encontrar a tradução do título como Nietzsche, a genealogia e a história, mas o título do original publicado pela P.U.F em 1971 não tem o aditivo "e". É notável o primor e o valor literário com que Foucault elabora os títulos de seus

126 | Cad. Nietzsche, Guarulhos/Porto Seguro, v.39, n.2, p. 125-160, maio/agosto, 2018. 
Nietzsche, a genealogia, a história: Foucault, a genealogia, os corpos

com o título Foucault, a genealogia, os corpos que, ao menos entre os anos 1970-1976, a genealogia do poder e do sujeito em Foucault se mostra uma genealogia de corpos históricos. A proposta mais básica desta análise se resume ao seguinte: Foucault não lê Nietzsche, não faz exatamente uma gênese do procedimento genealógico. Ele se apropria de um modo muito particular da genealogia de Nietzsche, acentuando-a como crítica dissociativa do sujeito como corpo. Sujeito que tem sua efetividade na luta que os corpos são na história.

\section{A autossuspensão da genealogia}

O colóquio em homenagem a Jean Hyppolite realizado em 1969 na École Normal Supérieur reuniu Louis Althusser, Suzanne Bachelard, Michel Henri, Jean Laplanche, Jean-Claude Pariente e Michel Serres. Nele Foucault apresentou seu Nietzsche, a genealogia, a história, um dos trabalhos que fizeram alguns estudiosos a datar a denominada guinada genealógica do pensar foucaultiano. Este trabalho foi dividido por Foucault em 7 partes. Resumidamente, temos uma espécie de introdução a partir da ideia de genealogia cinzenta como abertura do trabalho na qual Foucault compreende-a como uma oposição à pesquisa da origem. Na segunda parte, um longo trabalho com o vocábulo Ursprung cuja finalidade é tematizar e desenvolver esta recusa da origem que faz a genealogia. Na terceira parte, por um viés analítico sobre alguns vocábulos no alemão que Nietzsche utiliza para designar a pesquisa propriamente genealógica, há todo um trabalho sobre a genealogia como Herkunft e, na quarta

\footnotetext{
trabalhos. Não seria diferente com este: acontece que este título expõe o movimento argumentativo do texto que originalmente foi uma conferência. Foucault se desloca de uma caracterização da genealogia em Nietzsche, conforme um longo trabalho com os vocábulos que designam origem no alemão, em direção a uma reavaliação mais geral da ideia de história no pensamento de Nietzsche. Este movimento expressa uma reversibilidade entre genealogia e história: aquela, ao ser "lida" com uma precisão intertextual vai iluminar ou mesmo conduzir o retorno de Foucault às interpretações dadas por Nietzsche na segunda das Considerações Extemporâneas. Daí que o e interposto no título não nos parece fazer jus ao movimento argumentativo do pensador.
}

Cad. Nietzsche, Guarulhos/Porto Seguro, v.39, n.2, p. 125-160, maio/agosto, 2018. 
Ribeiro, C. E.

parte, como pesquisa da Entstehung. Na quinta parte, Foucault elabora o modo como a genealogia é uma crítica da própria ideia de história, isto é, a wirkliche Historie seria o modo conforme o qual Nietzsche faz uma genealogia da história, uma espécie de dobra da história efetiva sobre a história dos historiadores. ${ }^{3} \mathrm{Na}$ sexta parte, encontraremos o mesmo tema da quinta parte posta diante de uma nova problematização: como a genealogia poderia ainda ser histórica se a história foi entendida genealogicamente, por Nietzsche, como possuidora de um sentido histórico que, na verdade, é supra histórico. Se dependente de toda uma filosofia da história que a teria convertido em fabulação metafísica, como a genealogia produz o seu sentido histórico? Na sétima parte, Foucault responde propriamente esta pergunta mostrando que há três usos do sentido histórico em Nietzsche. Eles se oporiam às modalidades platônicas de história e que, no fundo, corresponde à retomada que o próprio pensador alemão faz das modalidades de história definidas na segunda das Considerações Extemporâneas.

No presente trabalho, atenho-me à análise das quatro primeiras partes. É nelas que Foucault deixa transparecer sua compreensão mais básica da genealogia nietzschiana.

$* * *$

Foucault inicia sua exposição pela referência ao Prólogo da Genealogia da moral, partindo da ideia de genealogia cinza apresentada por Nietzsche no parágrafo 7. Nesta passagem, depois de colocada em discussão a própria origem de sua pesquisa genealógica dos valores e de ter levantado a crítica aos psicólogos ingleses, Nietzsche declara: "Meu desejo, em todo o caso, era dar a um olhar tão agudo e imparcial uma direção melhor, a direção da efetiva história da moral, prevenindo-o a tempo contra essas hipóteses inglesas que se perdem no azul" (GM/GM, Prólogo, 7 KSA 5.254).

3 M. Foucault, 2001, p. 1014.

128 | Cad. Nietzsche, Guarulhos/Porto Seguro, v.39, n.2, p. 125-160, maio/agosto, 2018. 
Nietzsche, a genealogia, a história: Foucault, a genealogia, os corpos

Como sabemos, a genealogia é cinza porque ela nasce como a discordância frontal, desenvolvida por Nietzsche no início da I dissertação da Genealogia da moral, deste azulado do princípio de utilidade como fundamento da moral. Trata-se da discordância de Nietzsche em fundar a moral em uma suposta ação não-egoísta que, sendo primeiro louvada e depois esquecida como tal, teria se cristalizado, por hábito da valoração, como um bem. Segundo esta gênese da moral, na compreensão de Nietzsche, aquilo que foi tido por bom teria sido, então, sentido definitivamente como bom segundo um mero processo de assentamento da utilidade (ou um tosco processo, como qualifica Nietzsche) por parte daqueles que, originalmente, teriam valorado o não-egoísmo como um alto valor. $\mathrm{O}$ valor da utilidade será negado por Nietzsche como origem do bom por sua forte carga de a-historicidade:

temos aí "a utilidade", "o esquecimento" "o hábito" e por fim "o erro", tudo servindo de base a uma valoração da qual o homem superior até agora teve orgulho, como se fosse um privilégio do próprio homem. Este orgulho deve ser humilhado, e esta valoração desvalorizada: isso foi feito?... (GM/ GM I, 2 KSA 5.259).

Nietzsche admite que o pior defeito desta hipótese não seja sua a-historicidade, mas sim o problemático contrassenso psicológico presente no fato de não se explicar sobre o esquecimento desta utilidade original: o que teria sido este erro? Como se esquecera o valor do útil? Justamente a elaboração deste ponto é tarefa da primeira dissertação da Genealogia da moral, por meio do perspectivismo dos pares disjuntivos "bom e ruim" e "bom e mau".

Segundo Foucault, e esta é a abertura emblemática da sua conferência, a genealogia é cinza porque ela é minuciosamente documentária, ou seja, ela porta algo como uma suspensão de si mesma ao se preocupar com a minúcia do saber, com o acúmulo que, no fim das contas, é uma espécie de acúmulo documental de toda origem. 
Ribeiro, C. E.

É importante explicitar que Foucault é sensível ao modo como a genealogia logra "realçar" sua tarefa documental, cinzenta, segunda uma prévia desvalorização do valor da utilidade. Foucault retoma este aspecto, parodiando Nietzsche: "Paul Rée se engana, como os ingleses, ao descrever gêneses lineares, ao ordenar, por exemplo, toda a história da moral através da preocupação com o útil (...)" 4 C Contudo, a "indecifrável escrita hieroglífica do passado moral humano" (GM/ GM, Prólogo, 7 KSA 5.254) é cinza para Foucault porque, acima de tudo, a agudeza e a imparcialidade da genealogia se mostram melhor definidas numa espécie de princípio de autossuspensão que a genealogia acarreta.

O interesse de Foucault, nas primeira e segunda partes de sua conferência é, portanto, dar o tom de sua interpretação centrada na ideia de genealogia como oposição à pesquisa da origem que, no limite, é a necessidade criada, já pela arqueologia de Foucault de, ao praticar a história de discursos, desconstrui-los.

Gostaria de mostrar que Foucault está legitimado nesta perspectiva que me parece advir da autossuspensão que o próprio Nietzsche oferece a seu método de trabalho. Este aspecto autossupensivo, que é sugerido por Foucault nos três parágrafos iniciais do texto, se desenvolve ao longo da segunda parte da conferência de Foucault. Julgo importante oferecer previamente elementos que justifiquem melhor, em Nietzsche, esta leitura porque, no texto de Foucault, ela não está desenvolvida em relação à Genealogia da moral.

$\mathrm{O}$ começo da genealogia se coloca, assim, de dois modos: quando Nietzsche elabora, na abertura do Prólogo da Genealogia da moral, um tipo de subjetividade atual vazia e, depois, construindo um espelhamento desta vacuidade do eu-genealogista no próprio percurso vivencial de Nietzsche que é retraçado no Prólogo.

Vejamos o primeiro ponto. É bastante clara a estratégia textual de Nietzsche no parágrafo 1 do Prólogo: para começar sua grande

4 M. Foucault, 2001, p. 1004.

130 | Cad. Nietzsche, Guarulhos/Porto Seguro, v.39, n.2, p. 125-160, maio/agosto, 2018. 
Nietzsche, a genealogia, a história: Foucault, a genealogia, os corpos

investigação sobre o valor dos valores, Nietzsche se põe a descerrar as cortinas da moral ocidental referindo-se à questão mais fundamental que a caracteriza, a relação moral e conhecimento. Em outros termos, a moral e o próprio modo de vida filosófico são, em certo sentido, identificados. Na passagem em questão, é uma grande recordação sobre o passado filosófico. Foi o pensamento socrático-platônico que associou definitivamente filosofia e moral, o que resultaria para a história da moral na afirmação incondicional, dogmática de que todo pensamento está submetido a um determinado valor de conhecimento, o valor verdadeiro.

Verdade e moral surgem, pois, como pressupostos primeiros da Filosofia e se tornam o genealogista seu ponto de ataque. É nele que Nietzsche apresenta o problema impensado da relação entre o conhecimento de nós mesmos e nossas verdades. Afirma que “de nós mesmos somos desconhecidos". Não é que os filósofos não detivessem o conhecimento de suas verdades. Não é que simplesmente eles se enganaram ao trilhar, por séculos, o "daimon" socrático. É que este si mesmo foi a história de um grande estreitamento de um descuido de si. ${ }^{5}$ Os filósofos padeceram de um tipo de desconhecimento, de um defeito de origem: de si próprios eram desconhecidos, o que implica, logo se pode perceber, na mais flagrante contradição com o preceito délfico fundador da filosofia, o conhece-te a ti mesmo. Tudo o que a filosofia pretendeu conhecer passa a se identificar a um profundo desconhecimento:

Nós, homens do conhecimento, não nos conhecemos; de nós mesmos somos desconhecidos - e não sem motivo. Nunca nos procuramos: como poderia acontecer que um dia nos encontrássemos? Com razão alguém disse: "onde estiver teu tesouro, estará também teu coração". Nosso tesouro está onde estão as colmeias do nosso conhecimento. Estamos sempre a caminho delas, sendo por natureza criaturas aladas e coletoras do mel do espírito,

5 Esta é uma das teses mais originais do pensamento de Foucault que vai mostrar no curso $A$ Hermenêtica do sujeito como o conhecimento de si socrático é uma espécie de variante do cuidado de si no mundo clássico grego. Sócrates aparece como o mestre do cuidado de si (Cf. M. Foucault, 2006).

Cad. Nietzsche, Guarulhos/Porto Seguro, v.39, n.2, p. 125-160, maio/agosto, 2018. 
Ribeiro, C. E.

tendo no coração apenas um propósito - levar algo "para casa". Quanto ao mais da vida, as chamadas "vivências", qual de nós pode levá-las a sério? Ou ter tempo para elas? Nas experiências presentes, receio, estamos sempre "ausentes": nelas não temos nosso coração — para elas não temos ouvidos (GM/GM Prólogo, 1 KSA 5.247).

Por que Nietzsche abre sua genealogia afirmando nosso desconhecimento moral? Para que seu leitor esteja alerta a um perigo: é preciso que estejamos permanentemente numa atitude de desconfiança e distanciamento de nós mesmos para que se comece uma nova tarefa. Para emboscar a verdade, como valor que está sempre pronto para nos definir em absoluto, a genealogia tem um princípio primeiro: suspender-se pela afirmação de sua própria suspeita diante da verdade dos filósofos. Por isso lemos no parágrafo 1 do Prólogo que estamos ausentes no presente do conhecimento.

Há algo a mais neste desconhecimento, contudo. Este desconhecimento de si encontra um instante no qual os "os sinos acabam de estrondear no ouvido as doze batidas do meio-dia, e súbito acorda e se pergunta "o que foi que soou?". Este momento é quando nos perguntamos "perplexos inteiramente, "o que foi que vivemos?", e também "quem somos realmente?", e em seguida contamos, depois, como disse, as doze vibrantes batidas de nossa vivência, da nossa vida, do nosso ser - ah! e contamos errado...(GM/ GM, Prólogo, 1 KSA 5.248). ${ }^{6}$

É preciso notar que a ocorrência da expressão homens do conhecimento vem sem aspas enquanto que a expressão homem do desconhecimento, com aspas. Há uma distinção em jogo nesta mudança, sobretudo se compreendermos o pensamento deste filósofo como uma constante experimentação ou ensaio de pensamentos que se efetiva, entre outros, por meio do deslocamento metafórico. A expressão homem do conhecimento sem aspas expõe o sentido tradicional que

6 Todas a passagens citadas das obras publicadas de Nietzsche são traduzidas por Paulo César de Souza, conforme os livros indicados nas referências bibliográficas.

132 | Cad. Nietzsche, Guarulhos/Porto Seguro, v.39, n.2, p. 125-160, maio/agosto, 2018. 
Nietzsche, a genealogia, a história: Foucault, a genealogia, os corpos

define a condição do filósofo. Este é, em princípio, o homem que deve conhecer a verdade, ou seja, homem cuja vida se orientou inteiramente para esta exterioridade que o determina. Diferentemente, "Homens do desconhecimento" é um uma intervenção linguística de Nietzsche a fim de alterar a finalidade da vida filosófica. Homens que, agora, vão se reconhecer como ausentes nas experiências novas que, sem saber, estão a construir; homens que são do desconhecimento porque errantes e longe de si mesmos quando se trata de inventar as verdades que projetam sobre si. $\mathrm{O}$ eu-genealogista parecer figurar-se nestes "homens do desconhecimento": começar a tarefa nova sem saber-se nela.

Esta ausência não é um fingimento de não partir de si mesmo e de um ponto da história. Talvez seja o escrito de Nietzsche no qual mais fale como autor, por isso, por exemplo, parte de um ponto conhecido da história que é claramente a crítica ao utilitarismo, talvez o ponto histórico mais próximo de sua genealogia, mas que é também o ponto a ser criticado pela sua a-historicidade e psicologia grosseiras. Este começo atual é suspensivo porque se elabora como uma lacuna ou como uma não coincidência entre o homem do conhecimento e os "homens do desconhecimento", o que permite falarmos em um conhecimento do desconhecido de si mesmo. Nietzsche nesta abertura da Genealogia da moral propõe, portanto, uma atualidade como ausência subjetiva. Daí a necessidade de o genealogista, neste Prólogo, "recuperar-se". Ele deve retomar o que ele é por aquilo que foram suas vivências: "Quanto ao mais da vida, as chamadas "vivências", qual de nós pode levá-las a sério?" (GM/GM, Prólogo 1, KSA 5.247). Logo, Nietzsche vai assumir uma revisitação do modo como ele, esvaziado de si no instante de abertura do escrito, começou algo novo. Retomará seu percurso intelectual, lembrará dos passos que deu para chegar na sua genealogia da moral.

É por ela que, de modo não explícito, Foucault está chegando à genealogia de Nietzsche. No diapasão do pensador francês, a 
Ribeiro, C. E.

genealogia é vista, de antemão, como suspensão sistemática dos começos, especialmente do começo da própria subjetividade.

\section{A urdidura intertextual foucaultiana}

Antes, porém, de descrever como se desdobram este valor autossupensivo da genealogia para Foucault, é importante assinalar o procedimento muito particular a ele de lidar com os textos de Nietzsche. Um aspecto aparentemente circunstancial nesta primeira brevíssima parte de Nietzsche, a genealogia, a história em que a ideia de genealogia cinza é convocada revela um dado notável. Nela há duas notas de rodapé que citam diretamente trabalhos do pensador alemão, mas que não vêm da Genealogia da moral. A passagem é seguinte: "A genealogia "deve construir seus "monumentos ciclópicos" não a golpes de "grandes erros benfazejos", mas de "pequenas verdades inaparentes estabelecidas por um método severo". ${ }^{7}$ Chama a atenção o fato de Foucault mencionar, inicialmente, a Genealogia da moral e, contudo, citar outros trabalhos. A expressão monumentos ciclópicos é retirada do aforismo 7 de Gaia ciência enquanto que as duas outras passagens são citações do aforismo 3, do capítulo I de Humano, demasiado humano.

Foucault elabora uma justaposição de passagens o que, em princípio, incita seu leitor a pensar que um trabalho intratextual e, talvez até exegético, sobre a genealogia será feito. Se formos ao contexto dos escritos nietzschianos de onde as passagens foram retiradas, logo saberemos que elas são temática e conceitualmente orientadas por diversos elementos cuja complexidade Foucault, de certo modo, procede a uma redução, recorrendo a breves citações. Este caráter episódico se repetirá com relação às demais referências aos trabalhos de Nietzsche durante Nietzsche, a genealogia, a história.

7 Tomamos a tradução dessa passagem de Roberto Machado. FOUCAULT, Michel. Microfísica do poder. Trad. Roberto Machado. 21. ed. Rio de Janeiro: Graal, 2005.

134 | Cad. Nietzsche, Guarulhos/Porto Seguro, v.39, n.2, p. 125-160, maio/agosto, 2018. 
Nietzsche, a genealogia, a história: Foucault, a genealogia, os corpos

Tal modo de trabalhar serve para Foucault, no fundo, construir seu próprio mosaico sobre a genealogia nietzschiana. Apresento rapidamente como este recurso está estruturado e que se repete por toda a escrita.

Em A gaia ciência, o aforismo em questão se intitula "Algo para homens trabalhadores". Nietzsche propõe nele uma reflexão sobre a tarefa do estudioso da moral. Este algo para trabalhadores é uma nova tarefa que deve ser executada sobre "todas as espécies de paixões", isto é, Nietzsche associa a história das coisas morais ao imperativo de pesquisar minuciosamente as paixões humanas, o que acarreta uma enorme ampliação da tarefa daqueles que querem estudar "as coisas morais". Um número grande de possibilidades de histórias é ali antevisto por Nietzsche. $\mathrm{O}$ ponto de virada da argumentação se nota no instante em que o pensador, multiplicando as possibilidades históricas, coloca a exigência de uma ampla pesquisa sobre tudo aquilo que os homens tomaram como suas "condições de existência". É bastante provável que possamos ouvir nesta passagem a ideia de valor atuando. Tanto é que esta pesquisa deveria, então, ser também uma "demonstração dos motivos para a diferença de clima moral (Por que brilha aqui este sol de um juízo moral e medida de valor fundamental - e ali aquele outro?") (FW/GC 7 KSA 3.379). A passagem traz a imensa originalidade de uma história da moral que, como crítica do valor dos valores nos diversos campos que a história pode atuar, é inteiramente motivada por uma experimentação sobre a própria possibilidade de história.

A expressão que Foucault cita surge na última frase destas considerações do aforismo. É o momento em que Nietzsche está elaborando uma consequência a respeito da amplíssima história da moral sobre a qual conjecturou: se ela fosse realizada, se estes trabalhos todos de pesquisa sobre aquilo que os homens sentem como sua condição de existência (e que para Nietzsche significa que a ciência poderia “oferecer objetivos para ação"), então: 
Ribeiro, C. E.

caberia uma experimentação que permitiria a satisfação de toda espécie de heroísmo, séculos de experimentação, que poderia deixar na sombra todos os grandes trabalhos e sacrifícios da história até o momento. A ciência ainda não ergueu suas construções ciclópicas (Cyclopen-Bauten) até hoje; também para isso chegará o tempo" (FW/GC 7 KSA 3.380).

Vamos à outra passagem citada por Foucault, a de Humano, demasiado humano, o aforismo 3 intitulado "Estima das verdades despretensiosas". Nietzsche põe-se a falar sobre o modo pelo qual uma cultura superior estima suas verdades. Os "tempos e homens metafísicos e artísticos" estimam erros, afirma Nietzsche, que "ofuscam e alegram" enquanto que a cultura superior é rigorosa em estimar "pequenas verdades inaparentes (sans apparence). A passagem citada por Foucault é esta: a cultura superior tem como marca "estimar as pequenas verdades despretensiosas achadas com método rigoroso" (MA I/HH I, 3 KSA 2.25). ${ }^{8}$

Se tais passagens tratam de assuntos tão distintos, por que Foucault as retoma para definir a recusa da origem? Porque, mesmo tão distintas em seus pormenores e plenas de assuntos que Foucault certamente deixa de lado, elas têm um fundo de significado que remete a um conceito comum: o de positividade do erro que é justamente o valor suspensivo presente na crítica genealógica. ${ }^{9} \mathrm{O}$ estudioso

8 Trata-se da expressão unscheinbaren Wahrheiten. Foucault traduz como vérites sans apparence e o tradutor brasileiro verdades despretensiosas. NIETZSCHE, F. Humano, demasiado humano. Tradução, notas e posfácio de Paulo César de Souza. São Paulo: Companhia das Letras, 2000, p. 17. Na tradução francesa encontramos uma outra solução: verdades discretas (NIETZSCHE, F. Humain, trop humain; un livres pour esprits libres. textes et variantes établis par Giorgio Colli et Mazzino Montinari ; traduits de l'allemand par Robert Rovini. Paris: Gallimard, 1968, p. 33).

9 A temática é extensa demais para desenvolvermos aqui. Vamos apenas acenar que Nietzsche explicita a dimensão disruptiva da crítica genealógica segundo a qual o $N$ ão tem a forma positiva de uma abertura experimental onde se enceta a transvaloração: "Eu sou, no mínimo, o homem mais terrível que até agora existiu, o que não impede que eu venha a ser o mais benéfico. Eu conheço o prazer de destruir em um grau conforme à minha força para destruir - em ambos obedeço à minha natureza dionisíaca, que não sabe separar o dizer Sim do fazer o Não. Eu sou o primeiro imoralista: e com isso o destruidor par excellence. (EH/EH, Por que sou um destino, 2 KSA 6.366). NIETZSCHE, F. Ecce Homo; Como alguém se torna o que é. Tradução de Paulo César de Souza. 2. ed. São Paulo: Companhia das Letras, 1995, p. 110).'

136 | Cad. Nietzsche, Guarulhos/Porto Seguro, v.39, n.2, p. 125-160, maio/agosto, 2018. 
Nietzsche, a genealogia, a história: Foucault, a genealogia, os corpos

das coisas morais, vislumbrado pelo autor de $A$ gaia Ciência, deve considerar a multiplicidade de histórias que pode praticar desde que ele perceba todos os tipos de paixões; elas que se apresentam como condições de existência dos homens. Ora, se ele concluir tal pesquisa, então, terá suspendido a história e recomeçado, terá deixado "na sombra todos os grandes trabalhos e sacrifícios da história até o momento" (FW/GC 7, KSA 3.380). A ciência terá condições de, assim, erguer suas "construções ciclópicas" porque ela efetuou um minucioso trabalho sobre o "caráter errôneo de todos esses motivos e naturezas do juízo moral". (FW/GC 7 KSA 3.379) Mas como o estudioso da moral colocará em prática este percurso disruptivo do erro? Com Humano, demasiado humano, Foucault responde: segundo verdades parciais, despretensiosas, sem uma aparência final, ou seja, tomando o erro com o rigor que está inscrito em sua própria parcialidade, acatando a "inaparência" do próprio erro.

Por isso, o pensador francês não se põe a avaliar os vários conceitos expostos nas passagens, nem os situará em relação às preocupações nietzschianas com a pesquisa da moral; tampouco, quando cita diretamente Nietzsche, vamos ler um comentário especifico de uma obra em particular. Foucault é, neste trabalho sobre a genealogia, um extrator de sentidos gerais conforme as referências que escolhe tramar com os escritos de Nietzsche. Aquele grande viés (o de um efeito auto suspensivo da genealogia) é, com isso, confirmado sob uma urdidura intertextual que Foucault vai construindo ao "amarrar" diferentes passagens cujo desdobramento, nesta abertura de sua análise, é precisamente mostrar que o grande pressuposto da genealogia é ser uma crítica positiva da moral desde de um ponto de vista em suspenso. Daí a necessidade de desdobrar esta temática apresentada na primeira parte para estudar, mais de perto, quais os postulados suspensivos a genealogia admitiu. Foucault o fará pelo recurso aos vocábulos origem no alemão. 
Ribeiro, C. E.

\section{A oposição à Ursprung: três postulados suspensivos}

O demorado trabalho que Foucault faz com o emprego da palavra origem na obra de Nietzsche não é apenas uma precisão técnica de vocábulo na língua alemã. Foucault aponta que o vocábulo Ursprung se alterna com o uso de outros termos que significam origem. Ele verifica, por um lado, que há um sentido não marcado para Ursprung servindo a Nietzsche a diferentes fins argumentativos. Por outro lado, haveria um sentido marcado no uso de Ursprung quando "ocorre efetivamente que Nietzsche a coloque em oposição a um outro termo". Então, Ursprung aparecerá, em diferentes escritos de Nietzsche, em relação diferencial a algum outro termo utilizado para significar origem. Por exemplo, assinala Foucault: “o primeiro parágrafo de Humano, demasiado humano coloca face a face a origem miraculosa (Wunderursprung) que busca a metafísica e as análises de uma filosofia histórica que coloca questões über Herkunft und Aufgang". " São dados outros exemplos tomados dos escritos de Nietzsche, fundamentalmente em Aurora, A gaia ciência, Genealogia da moral e Crepúsculo dos Ídolos.

Mas é no Prólogo de Genealogia da moral que Foucault percebe a alteração muito particular que Nietzsche fez em relação a Ursprung. Nietzsche diz no parágrafo 2 do Prólogo: "Meus pensamentos sobre a origem (Herkunft) de nossos preconceitos morais — tal é o tema deste escrito polêmico — tiveram sua expressão primeira, modesta e provisória na coletânea de aforismos que leva o título Humano, demasiado humano" (GM/GM Prólogo, 2 KSA 5.248). Foucault observa que Nietzsche utiliza então Herkunft. Na sequência, Nietzsche volta a utilizar Ursprung, mas agora para refazer o caminho que levou até ali, até a Genealogia da moral.

Integralmente a passagem do parágrafo 3 do mesmo Prólogo, lemos:

10 M. Foucault, 2001, p. 1005.

138 | Cad. Nietzsche, Guarulhos/Porto Seguro, v.39, n.2, p. 125-160, maio/agosto, 2018. 
Nietzsche, a genealogia, a história: Foucault, a genealogia, os corpos

Por um escrúpulo que me é peculiar, e que confesso a contragosto - diz respeito à moral, a tudo o que até agora foi celebrado na terra como moral —, escrúpulo que surgiu tão cedo em minha vida, tão insolicitado, tão incontido, tão em contradição com ambiente, idade, exemplo, procedência, que eu quase poderia denominá-lo meu "a priori" — tanto minha curiosidade quanto minha suspeita deveriam logo deter-se na questão de onde se originam verdadeiramente nosso bem e nosso mal. De fato, já quando era um garoto de treze anos me perseguia o problema da origem (Ursprung) do bem e do mal: a ele dediquei, numa idade em que se tem "o coração dividido entre brinquedos e Deus", minha primeira brincadeira literária, meu primeiro exercício filosófico — quanto à "solução" que encontrei então, bem, rendi homenagem a Deus, como é justo, fazendo-o Pai do mal (GM/GM Prólogo, 3 KSA 5.248).

Voltando a um trabalho escolar que realizou quando tinha treze anos ${ }^{11}$, Nietzsche o caracteriza como uma tentativa juvenil de Ursprung, de ter atribuído a origem do mal a Deus. No aforismo seguinte, o filósofo alemão continua esta espécie de histórico sobre como nasceu sua pesquisa sobre a origem dos preconceitos morais, mas agora assinalando que em Humano, demasiado humano ele levava em frente o desenvolvimento de uma Herkunfthypothesen: "Foi então que, como disse, pela primeira vez apresentei as hipóteses sobre origens a que são dedicadas estas dissertações (...) (GM/GM Prólogo KSA 5.251)". O que Foucault salienta é o fato de Nietzsche, ao retornar a Humano, demasiado humano, alterar o vocábulo de Ursprung para Herkunft. A palavra efetivamente utilizada lá em Humano, demasiado humano não era Herkunft, mas sim Ursprung. Mas Nietzsche altera o vocábulo.

Foucault está bastante ciente sobre este fato: a oposição é construída retrospectivamente. Nietzsche retorna ao escrito anterior, retorna a Humano demasiado humano, alterando o vocábulo para, ao olhar em retrospectiva, fingir que era outro já lá no seu projeto de

11 Montinari informa que esse texto de juventude se perdeu. Nietzsche chega a fazer referência a ele em outros momentos Cf. na KGW: IV, 3, p. 362ss KGW, I, P. 18 5[16].

Cad. Nietzsche, Guarulhos/Porto Seguro, v.39, n.2, p. 125-160, maio/agosto, 2018. 
Ribeiro, C. E.

origem dos valores: "como se à época da Genealogia, e neste ponto do texto, quisesse enfatizar uma oposição entre Herkunft e Ursprung que ele não tinha trabalhado 10 anos antes". Com isso Foucault pode, se não garantir, ao menos desconfiar que, a partir da Genealogia do moral, haverá um uso marcado sobre a ideia de origem. ${ }^{12}$

Uma interpretação crítica desta desconstrução é feita pelo trabalho de John Pizer The use and abuse of "Ursprung" on Foucault's Reading of Nietzsche. Pizer vai desenvolver uma perspectiva bastante acurada de como Foucault, embora perceba muito bem o uso marcado de Ursprung, acaba fazendo de Nietzsche só "um genealogista antiUrsprung por excelência"13. Em outros termos, Pizer mostra que a primeira e segunda partes do trabalho de Foucault negligencia o fato de Nietzsche utilizar Ursprung como uma categoria não de oposição à metafísica da origem, mas de construção dialética da origem. Por exemplo, recorrendo à seção 8 da segunda Dissertação, espécie de resumo da Ursprung da culpa, Pizer contraria Foucault:

Foucault cita essa passagem, mas apenas como um exemplo do uso "marcado" de "Ursprung" em Nietzsche. De fato, "Ursprung", e não "Entstehung", significa mais verdadeiramente o lócus do interstício onde forças morais concorrentes emergem, lutam, desaparecem e dominam. "Ursprung" fornece a fundação para uma genealogia da moral. ${ }^{14}$

Pizer é convincente nesta posição desenvolvida, apresentando fartamente passagens inteiras em Nietzsche nas quais Ursprung surge como operação crítica na genealogia, funcionando no seu interior como uma engrenagem. Mas quando Foucault realça, como veremos, três efeitos autossuspensivos da Ursprung é um trabalho similar que

12 A referência em questão é Humano, demasiado humano 92: Origem da justiça (Ursprung Gerechtigkeit). Foucault dirá em nota que no texto da Genealogia da moral o emprego destes vocábulos será um tanto equivalente, o que certamente enfraquece seu argumento: M. Foucault, 2001, p. 1006, cf. nota 2).

13 J. Pizer, 1990, p. 463.

14 J. Pizer, 1990, p. 466.

$140 \mid$ Cad. Nietzsche, Guarulhos/Porto Seguro, v.39, n.2, p. 125-160, maio/agosto, 2018. 
Nietzsche, a genealogia, a história: Foucault, a genealogia, os corpos

ele propõe, muito embora construindo sentidos de modo livremente intertextual. Assim, não vemos Foucault procurando qualificar a Ursprung como um "erro epistemológico"15 expresso numa crítica à metafísica da origem como entende Pizer. Antes, procura assinalar o efeito autossuspensivo da genealogia sob a forma de três postulados que apresentarei em linhas.

Primeiro postulado: a recusa da Ursprung serve para obter um efeito suspensivo da origem e dele fazer uso:

se o genealogista tem o cuidado de escutar a história em vez de crer na metafísica, o que ele aprende? Que por trás das coisas há "algo completamente distinto": não absolutamente seu segredo essencial e sem data, mas o segredo de que elas são sem essência ou que sua essência foi construída peça por peça a partir de figuras que lhe eram estranhas. ${ }^{16}$

Foucault recorre aos seguintes textos. O breve aforismo 123 de Aurora sobre como a razão é uma espécie de razoável do acaso: "Razão - como veio a razão ao mundo? Como é justo, de maneira irracional, por um acaso. Seria preciso decifrá-lo, como um enigma" (A/A II, 123 KSA 3.116). Recorre a $O$ andarilho e sua sombra, aforismo 9 ("Onde se originou a teoria do livre arbítrio") em que Nietzsche desenvolve o tema liberdade ligado ao sentimento de viver (WS/AS 9 KSA 2.545). Suspender a origem é um procedimento tanto para desfazer a história como um começo autoidentitário, quanto assinalar a abertura do disparate. Conforme os textos citados, disparate da razão que nasce do acaso do razoável; disparate do apego ao rigor do método científico, que se remonta, no limite, ao cientista como o defensor de sua verdade contra outras verdades; disparate da

15 J. Pizer, 1990, p. 475. Bastante curiosa é a análise de Pizer que, criticando Foucault, afirma explicitamente na mesma página 475 que Nietzsche não desafia a busca da origem, mas que "seria mais correto dizer que Nietzsche procura desmistificar a metafísica da "Ursprung", deslocando seu lócus do paraíso da plenitude metafísica para os interstícios entre ideologias antitéticas e egoístas". Esta é a tarefa não é inconsistente com a posição de Foucault.

16 M. Foucault, 2001, p. 1006.

Cad. Nietzsche, Guarulhos/Porto Seguro, v.39, n.2, p. 125-160, maio/agosto, 2018. 
Ribeiro, C. E.

liberdade que é apenas um sentimento de viver cuja apropriação política é orientada pelo afeto de mando ${ }^{17}$.

$\mathrm{O}$ segundo postulado suspensivo realiza-se sobre um absoluto superior. A origem é sempre uma exterioridade absoluta "antes da queda, antes do corpo, antes do mundo e do tempo", um começo que só uma teogonia poderia narrar. Recusar a origem é, por isso, tirar o homem do lado dos deuses, do lado de Deus e mesmo do lado do macaco para situá-lo na terra, o que implica encontrar o ponto mais humano da história, o próprio homem como condição construída em que estes absolutos (deuses, Deus e o macaco) representam apenas o exagero metafísico do homem sobre o homem. O "novo sentimento fundamental" do homem é uma "definitiva transitoriedade" (M/A 49 KSA 3.53). A atitude do genealogista é, para Foucault, a de uma contrariedade irônica: "a história ensina a rir também das solenidades da origem" 18 ou, para ir à citação direta feita por Foucault de $O$ andarilho e sua sombra, aforismo 3: "No início era - "Glorificar a gênese - É o broto metafísico que torna a rebentar quando se considera a história, e faz que no inicio de todas as coisas está o mais valioso e essencial" (WS/AS, 3 KSA 2.540)

Terceiro efeito suspensivo, por fim, o postulado sobre a questão da verdade: é necessário suspender o efeito da verdade que a origem como Ursprung acarreta. A pesquisa da origem é uma armadilha

17 Foucault parece evitar, por vezes, as passagens nas quais Nietzsche conceitua sua oposição à ideia de origem, preferindo os momentos em que o pensador articula, por meio de outro tema, uma oposição à pesquisa da origem. Talvez a prova mais certa desta espécie de contorno que Foucault faz seja o aforismo 44 de Aurora. Se Foucault trabalhou com o aforismo 123, como explicitamos, é porque a temática não é a origem, mas como a razão se origina e nasce do disparate do acaso. Ora, o aforismo 44 intitulado Origem e significado é, diferentemente, uma recusa da pesquisa da origem cujo tema é a própria ideia de origem: "Com a penetração da origem aumenta a insignificância da origem: enquanto o mais próximo, o que está em torno de nós, começa gradativamente a mostrar cores, belezas, enigmas e riquezas significativas, com que a humanidade antiga não sonhava (M/A I, 44 KSA 3.52). Tanto mais certo, portanto, que a apropriação que Foucault faz é, de fato, esta urdidura intertextual que, tramada pelas referências mais "operacionais" da pesquisa contra a origem, tem por finalidade haurir um sentido geral desta oposição.

18 M. Foucault, 2001, p. 1007.

142 | Cad. Nietzsche, Guarulhos/Porto Seguro, v.39, n.2, p. 125-160, maio/agosto, 2018. 
Nietzsche, a genealogia, a história: Foucault, a genealogia, os corpos

montada pelo modelo da verdade. A verdade é sempre um efeito de verdade que consiste em oferecer um saber presente finalizado. Ele se apresenta como possibilidade de veridição do discurso, mas este mesmo discurso nunca possui completamente a própria verdade. A origem "estaria na articulação inevitavelmente perdida em que a verdade das coisas se liga a uma verdade do discurso que logo a obscurece e a perde" 19 , ou seja, origem e verdade se autopreservam porque não se pode refutar o ponto de sua emersão já perdido, a junção imemorial verdade e discurso. Em outros termos, recusar a Ursprung é negar o postulado da vontade de verdade mostrando que esta é a história de um erro.

Os três postulados com seus efeitos suspensivos característicos ressoariam a contraposição feita por Nietzsche entre Ursprung e Herkunft: recusar a origem como história autoidentitária, recusar a origem como exterior absoluto e recusar a origem como vontade (incondicional) de verdade. Isto situa o genealogista em uma posição estratégica bastante determinada. Parafraseando Foucault, concluise: o genealogista situa-se nas "meticulosidades, nos acasos dos começos", está atento aos começos de modo escrupuloso "em sua derrisória maldade"; o genealogista está de tocaia para, vendo aparecer uma máscara, poder arrancá-la. Ele é como um exorcista que necessita conjurar a quimera da origem com a história. ${ }^{20}$

Enfim, nestas duas primeiras partes do trabalho de Foucault, um primeiro traço se estabelece da sua apropriação da genealogia de Nietzsche. Toda trama de citações feitas conduz ao seguinte: se o genealogista está espreitando os começos não é para simplesmente declará-los como falsos ou passiveis de serem meramente recusados. Com todo o efeito de acúmulo da massa documental sobre a qual o genealogista trabalha, sobre todos estes começos enganosos, trata-se de admitir um outro começo, mais efetivo, cuja preocupação não recai em

19 M. Foucault, 2001, p. 1007.

20 M. Foucault, 2001, p. 1008.

Cad. Nietzsche, Guarulhos/Porto Seguro, v.39, n.2, p. 125-160, maio/agosto, 2018. 
Ribeiro, C. E.

uma finalidade monótona, mas exibe a singularidade do acontecimento desde um retardar inevitável. Que se note: o genealogista como um anti-Ursprung é visto por Foucault precisamente para descobrir como certa origem se estruturou. Se Foucault não dá um sentido dialético a Ursprung é porque ela, ao exigir minuciosidade do saber, obstinação, erudição, paciência, é um modo estratégico de começar uma outra história. Portanto, é preciso reter este sentido geral dado por Foucault: a genealogia sempre abre com meticulosidade um fundo falso como sua estratégia (I).

\section{A pesquisa positiva da genealogia: Herkunft e Entstehung}

Na sequência, Foucault passa a definir a genealogia por meio da análise dos vocábulos Entstehung e Herkunft. A genealogia ligada ao vocábulo Herkunft tem quatro sentidos de procedência. Farei apenas uma síntese desses sentidos para passar a relação da Herkunf com o corpo.

Primeiro sentido. Foucault identifica em Nietzsche a procedência como tronco (souche) apoiando-se em A gaia Ciência e Além do bem e do mal (respectivamente, FW/GC348 e 349 KSA 3.583-586 e JGB/BM 260 KSA 5.208-212). Tal como a filologia e a linguística, que trabalham com a ideia de um grande grupo de línguas, a procedência se liga a um tronco que remotamente representa uma origem comum. Em um segundo sentido, a procedência tem uma lógica dispersiva do acontecimento, por isso ela é precisamente crítica. Seguir "o filão da procedência (provenance)" é “manter o que se passou na dispersão que lhe é própria". Nietzsche confere, como sabemos, um papel positivo à falha, ao erro, aos "acidentes", aos desvios que constituem apenas um ponto de chegada que não pode ser o termo invariável para avaliar o passado. Foucault marca aí o sentido da crítica genealógica por meio da ruptura nietzschiana

144 Cad. Nietzsche, Guarulhos/Porto Seguro, v.39, n.2, p. 125-160, maio/agosto, 2018. 
Nietzsche, a genealogia, a história: Foucault, a genealogia, os corpos

com nas dicotomias de valores típica do dogmatismo (GD/CI, A "razão" na filosofia, 4 KSA 6.76). Terceiro sentido. A procedência está associada ao termo Erbschaft, à herança. Mas a herança é, por assim dizer, o signo aparente de uma identidade sob o qual um indivíduo se insinua, como no caso da procedência do erudito (FW/ GC, 348 KSA 3.584). Nestes três primeiros sentidos, ainda que não se equivalham, eles têm em comum o caráter operacional acentuado por Foucault: a genealogia procede como busca de uma (i) raiz comum a fim de marcar (ii) uma ruptura nesta raiz que impõe algum tipo de (iii) individualização na história da moral.

Diferentemente, no quarto sentido da genealogia como Herkunft não se trata de acentuar o valor operacional da genealogia, mas de buscar, por assim dizer, os efeitos de uma origem. Foucault localiza o efeito de uma origem de modo duplo. Em continuidade da ideia de herança, a procedência denuncia um tipo que é um corpo. Foucault caracteriza a ideia de que a procedência se denuncia em corpos, se revela no processo fisiológico: "o corpo que sustenta, em sua vida e sua morte, em sua força e fraqueza a sanção de qualquer verdade e de qualquer erro, tal como sustenta também, e inversamente, a origem - procedência" ${ }^{21}$. Embora Foucault tenha ciência de que neste ponto esbarra na vontade de potência, não é nos termos desta doutrina que ele desenvolve este último sentido de procedência. Assim, o corpo como Herkunft para Foucault não está acentuado como vida fraca ou forte que denuncia a ascendência ou decadência da vida, mas é visto como marca ou o estigma dos acontecimentos em que estes critérios da ascendência ou decadência da vida está diluído, ou seja, o corpo é um efeito de luta.

A mesma busca pelos efeitos se faz na quarta parte da exposição de Nietzsche, a genealogia, a história. Foucault atravessa os sentidos da genealogia ligada ao vocábulo Entstehung. Ele é o lugar do embate: Entstehung é o "ponto de surgimento", o "princípio e a lei singular de

21 M. Foucault, 2001, p. 1010. 
Ribeiro, C. E.

um aparecimento"; o campo é efetivamente a cena de batalha. ${ }^{22}$ Dentro desta perspectiva mais geral do campo de batalha, a emergência é identificada sob três aspectos. Como o restabelecimento dos "diversos sistemas de submissão" (i). A emergência é também um "estado de forças" (ii) e aí temos a caracterização rápida, embora fundamental, a partir do aforismo 262 de Além do bem e do mal de um aspecto importante do estado de forças em luta. Ela é assinalada como um campo que compõem um jogo infinito, uma luta sem termo, ou seja, um combate não vetorial. Este estar diante de é muito importante para Foucault. ${ }^{23}$ A emergência é, por fim, sob um terceiro aspecto, a entrada em cena das forças (iii). Foucault desenvolve este último aspecto, desdobrando-o em três pontos: como lugar vazio da luta ("teatro sem lugar"); esta luta se resumiria à reposição da dominação, ou seja, é um jogo ininterrupto de dominação ("violência meticulosamente repetida"); este jogo ininterrupto da violência é concretizado pela apropriação de regras: um teatro de procedimentos cumpre com esta espécie de regra fundamental da coação a que obriga o campo de batalha, por meio da apropriação de sistemas de regras. ${ }^{\mathbf{2 4}}$

Tal como o corpo está acentuado em uma dimensão intersticial daquilo pelo que se luta, e destituído do critério de ascendência ou decadência da vida, a Entstehung é vista como a própria cena de batalha. Trata-se de dizer com ele de que modo as forças operam, como fazem emergir um campo no qual se desenvolve a luta. Este sentido é um espaço definido como limite de confrontação em que uma mesma peça se passa. Se o corpo é aquilo pelo que se luta, o campo de batalha é a cena vazia de um enfrentamento.

Assim, retenhamos estes dois novos sentidos mais gerais quanto à análise da genealogia. Como Herkunft: o corpo é interstício, espaço no qual emerge algo pelo que se luta (II) e Entstehung que se mostra

22 M. Foucault, 2001, pp. 1011-1012.

23 M. Foucault, 2001, pp. 1012-1013.

24 M. Foucault, 2001, pp.1012-1013.

146 | Cad. Nietzsche, Guarulhos/Porto Seguro, v.39, n.2, p. 125-160, maio/agosto, 2018. 
Nietzsche, a genealogia, a história: Foucault, a genealogia, os corpos

como o campo de forças, espaço de confronto efetivado por um teatro de procedimentos, de empoderamento de regras anônimas sempre repostas em uma cena possível (III).

Quero parcialmente concluir que a genealogia de Foucault, estudando estas dimensões da origem, da procedência e da emergência, se não negligencia o fato de ela estar marcada por assuntos fundamentais como o instinto e a teoria das forças, este uso acaba por refazer a genealogia como método a ser praticado por Foucault. Orientada pelos três enfoques que pontuei ao longo da argumentação, a genealogia foucaultiana poderia assim ser sintetizada:

I. O genealogista faz nascer um começo suspendendo toda "origem", opondo-se estrategicamente "à pesquisa da origem". A genealogia é, portanto, a escolha estratégica por um começo a ser a ele negado a origem, onde se abre a possibilidade de fazer um trabalho de procedência e emergência;

II. O corpo é uma marca ou o estigma dos acontecimentos; o corpo é interstício, espaço que emerge aquilo pelo que se luta, isto é, lugar vazio que dará chance a Foucault de fazer sua genealogia da subjetividade;

III. O campo de forças é um espaço de confronto efetivado por um teatro de procedimentos, de empoderamento de regras. A genealogia é a descrição minuciosa dos discursos que forjaram tais regras e tais empoderamentos de regras.

Este triplo enfoque estabelecido na interpretação da genealogia nietzschiana define uma parte de como procedeu a genealogia de Foucault, quero dizer, o tratamento singular dado à genealogia por ele. Será possível mostrar o aparecimento de tais traços nos cursos dados por Foucault no Collège de France. A genealogia de Foucault orienta uma pesquisa contra certa origem de um discurso, sob a crítica de um teatro de procedimentos em uma encenação que visa marcar o corpo ou em que um corpo se produz como resultado da 
Ribeiro, C. E.

cena. Cena que é o acontecimento deste corpo como história, como enfrentamento. Deve-se estar atento, contudo, para as consequências desta opção. Ao desligar o corpo de sua pluralidade instintual, ao privilegiar certo modo de operar genealógico, Foucault dá um passo em falso, ou como quer Pizer, padece de uma cegueira.

\section{O parti pris foucaultiano: analise da Entstehungherd}

Se deixássemos de lado o fato de Foucault tramar uma genealogia segundo certas motivações interpretativas, que aliás estão em construção para Foucault, poderíamos dizer que uma leitura mais rente ao texto de Nietzsche dificultaria um tanto as coisas para o pensador francês. Por isso, levanto um contraponto às análises de Foucault a fim de elucidar a construção do seu parti pris. Quando caracteriza tão belamente a emergência como "a entrada em cena das forças, é sua irrupção, o salto pelo qual elas passam dos bastidores ao palco cada qual com o vigor, a jovialidade que lhe é própria", Foucault dá como referência o parágrafo 2 da II dissertação da Genealogia da moral. Ele ressalta, a partir desta passagem, um aspecto desta entrada em cena das forças:

É o que Nietzsche chama Entstehungherd do conceito de bom, o que não é exatamente nem a energia dos fortes, nem a reação dos fracos, mas esta cena na qual eles se distribuem um diante dos outros, uns sobre os outros; é o espaço que os separa e se abre entre eles, o vazio através do qual eles trocam suas ameaças e suas palavras". ${ }^{25}$

Como já mencionei atrás, o ponto de apoio para Nietzsche começar sua genealogia do "bom e mau" e "bom e ruim" foi estabelecer uma crítica ao utilitarismo. Tendo reconhecido os psicólogos ingleses como "enigma nada pequeno" (GM/GM, I, 1 KSA 5.257) e tendo deles se afastado pela flagrante fragilidade histórica do princípio

25 M. Foucault, 2001, pp. 1012-1013, grifo meu.

148 | Cad. Nietzsche, Guarulhos/Porto Seguro, v.39, n.2, p. 125-160, maio/agosto, 2018. 
Nietzsche, a genealogia, a história: Foucault, a genealogia, os corpos

de utilidade, Nietzsche então apresenta o que seria a tal entrada em cena do conceito "bom" que Foucault enfatiza para caracterizar Entstehung como Entstehungsherd:

Para mim é claro, antes de tudo, que essa teoria busca e estabelece a fonte do conceito "bom" no lugar errado: o juízo "bom" não provém daqueles aos quais se fez o "bem"! Foram os "bons" mesmos, isto é, os nobres, poderosos, superiores em posição e pensamento, que sentiram e estabeleceram a si e a seus atos como bons, ou seja, de primeira ordem, em oposição a tudo que era baixo, de pensamento baixo, e vulgar e plebeu. Desse pathos da distância é que eles tomaram para si o direito de criar valores, cunhar nomes para os valores: que lhes importava a utilidade! (GM/GM I, 2, grifo meu).

O notável é que a passagem vem precisamente depois de algo muito próximo de uma cena que Nietzsche mesmo estabeleceu com a criação deste personagem, no plural, psicólogos ingleses. É no mínimo problemático desconsiderar, nesta passagem, que Nietzsche assevera que a Entstehungsherd do conceito bom está no lugar errado porque, quando pensado como valor da utilidade, se subtrai a história desse conceito. E se quiséssemos interpretar para ir em outra direção?

A Entstehungsherd do conceito bom, diferentemente de ser cena vazia e ausência da afirmação dos fortes e de reação dos fracos, é toda ela preenchida do critério pelo que se luta. É possível até ver aí algo comum uma contracena que identifica o confronto mesmo entre a genealogia da moral e a gênese da moral, entre a pesquisa crítica do valor dos valores e esta que se mitiga no autovalor da utilidade como forma atemporal do conceito bom. A passagem, assim, não elaboraria uma cena na qual o confronto é um face a face de uma cena vazia. É o próprio confronto que está se concretizando na abertura da Genealogia da moral. A sequência de perguntas que Nietzsche coloca em relação aos psicólogos ingleses não é uma indagação meramente retórica; é uma sequência de expectativas radicais para que "esses pesquisadores e microscopistas da alma sejam na verdade criaturas valentes, magnânimas e orgulhosas, que 
Ribeiro, C. E.

saibam manter em xeque seu coração e sua dor, e que se tenham cultivado a ponto de sacrificar qualquer desejo à verdade" (GM/ GM, I, 1 KSA 5.258). No entanto, como se sabe, são apenas sapos nadando no pântano homem.

Desta perspectiva, talvez possamos ler o vocábulo Entstehungsherd de outro modo. ${ }^{26}$ A tomada de partido de Foucault acentuou a dimensão de abertura de um espaço da luta, um nãoespaço, na expressão de Foucault, que claramente é uma ênfase dada aoface a face da luta. A favor de Foucault poderíamos dizer que, de fato, quando caracteriza esta luta das forças como a produção de um interstício, como "espaço que se divide e se abre entre eles", como o vazio desde o qual os adversários se enfrentam, o que há aí é a visão do perspectivismo nietzschiano. Mas se implicado na genealogia, já que valorar é sempre estruturar perspectivas de valor, a entrada em cena do conceito bom já pressuporia, não uma cena vazia, mas a crítica afirmativa contra o tipo fraco, neste caso, localizado de antemão por Nietzsche na figura dos psicólogos ingleses.

Um lado da pergunta genealógica é, de fato, como é o acento de Foucault, "sob que condições o homem inventou para si os juízos de valor "bom" e "mau"? e que valor têm eles?". Mas o outro lado estreitamente ligado ao primeiro: "Obstruíram ou promoveram até agora o crescimento do homem? São indícios de miséria, empobrecimento, degeneração da vida?" (GM/GM, "Prólogo", 3 KSA 5.249-250). A implicação disto é que a genealogia nietzschiana tem uma visada. Ela vai contar a história de uma vitória, a vitória escrava na moral e, só por isso, podemos desconfiar que genealogia e transvaloração de todos os valores não podem separar-se. Nietzsche deseja o filósofo

26 Apoiamos esta leitura na interpretação de Pizer: "A visão de Foucault de que "Entstehung" é um lugar (na verdade, um "não-lugar", uma pura distância) da luta e da disrupção é um pouco desmentida pelo fato de Nietzsche usar a forma predicativa deste substantivo no prefácio da Genealogia. Nietzsche procura enfatizar a busca pela ancestralidade ("Herkunft") dos preconceitos morais através do uso de uma metáfora orgânica. Ele se sente confiante na validade dos seus pensamentos precisamente porque eles não surgiram esporadicamente” (J. Pizer, 1990, p. 464).

150 | Cad. Nietzsche, Guarulhos/Porto Seguro, v.39, n.2, p. 125-160, maio/agosto, 2018. 
Nietzsche, a genealogia, a história: Foucault, a genealogia, os corpos

do futuro e sua genealogia se pretende também um abalo sísmico da civilização. Se ela localiza como Entstehung o campo de luta é porque há uma luta em curso: a Grande crítica pressuporia a Grande luta contra o ressentimento.

É preciso conceder a Pizer totalmente este ponto. Ele nos indica com precisão que a energia dos fortes é determinante do conceito de bom:

Embora Nietzsche, de fato, sobreponha as avaliações plebeias e nobres do bom no fragmento citado por Foucault, Nietzsche usa o termo "Entstehungsherd" exatamente no sentido inverso do que Foucault alega que ele (Nietzsche) usa. Nietzsche afirma que o "Entstehungsherd" do conceito de bom é procurado no lugar errado. Não surge primeiro como valor do fraco, mas do forte. É precisamente "a energia dos fortes" que Nietzsche situa o "Entstehungsherd" do conceito de bom. O lócus da erupção do choque entre moralidades contrastantes, o local onde Nietzsche sobrepõe as antíteses bem e mal não é um lugar de "Entstehung", mas de "Ursprung". ${ }^{27}$

Com isso, não se trata de dizer que Foucault se enganou sobre a leitura da genealogia nietzschiana. Com este exemplo, entretanto, é possível se certificar de que há ênfases decisivas para o modo como Foucault irá trabalhar em sua própria prática genealógica. O leitor de Nietzsche não estranhará alguém dizer que o corpo é o resultado da confrontação, a marca deixada na história e que o campo de forças é o lugar de confrontação. Mas certamente replicaria: qual corpo? Quais forças? Ou seja, perguntar-se-iam: promove ou obstrui a vida? Em suma, perguntaria, sob qual critério se faz efetivamente uma análise de Herkunft e Entstehung? Tanto mais nos certificamos disto ao vasculharmos as ocorrências do vocábulo Entstehungsheerd, ainda que não exaustivamente e apenas para ilustrar este ponto. $\mathrm{O}$ vocábulo também aparece em Nietzsche com a grafia Entstehungsherd (que é a grafia citada por Foucault). A dificuldade do vocábulo parece

27 J. Pizer, J. 1990, p. 465.

Cad. Nietzsche, Guarulhos/Porto Seguro, v.39, n.2, p. 125-160, maio/agosto, 2018. 
Ribeiro, C. E.

recair no termo Herd que pode expressar o foco ou a fonte de uma doença que, aliás, parecer ser o universo semântico mais usual de Nietzsche para o termo.

Na Genealogia da moral, além da Entstehungsheerd do conceito de bom já citado, temos: "Nesta esfera, a das obrigações legais, está o foco de origem desse mundo de conceitos morais: "culpa", "consciência", "dever", "sacralidade do dever" — o seu início, como o início de tudo grande na terra, foi largamente banhado de sangue" (GM/GM II, 6 KSA 5.300 grifos meus). Num fragmento póstumo da primavera de 1888 em que Nietzsche relaciona diretamente a arte (Kunst) à excitação do corpo (Leib) encontramos a conotação em questão. A passagem, inclusive, fala da Ursprung da arte como excitação muscular: "Toda arte atua como sugestão sobre os músculos e os sentidos que, originalmente (ursprünglich), são ativas nas disposições artísticas do homem ingênuo" (Nachlass/FP 1888, 14 [119], KSA 13.296). O termo surge então para descrever como o estado estético tem "uma superabundância de meios de comunicação" assim como possui "extrema receptividade aos estímulos e aos sinais". Nietzsche é incisivo: "É aqui que as línguas têm sua origem (Entstehungsheerd): a linguagem dos sons são também linguagens dos gestos e dos olhares" (Nachlass/FP 1888, 14 [119], KSA 13.296-297). Ainda em 1888, encontramos a expressão utilizada para compreender como a "representação de outro mundo" é sintoma da decadência ou ascendência de um povo. Nietzsche arrola os tipos que denunciam a criação deste "outro mundo": o filósofo, o religioso e o homem moral que ali são nomeados de os "focos (Entstehungsheerd) desta noção: "outro mundo" (Nachlass/FP 1888, 14 [168], KSA 13.353). Nietzsche na sequência também diz: "o que há de comum entre os três focos (Entstehungsheerd)... a brevidade psicológica, as confusões psicológicas" Nachlass/FP 1888, 14[168], KSA 13.354).

A fonte ou o foco da origem (a Entstehungsheerd da genealogia) não separa apreciação de valores e as condições fisiológicas em que

152 | Cad. Nietzsche, Guarulhos/Porto Seguro, v.39, n.2, p. 125-160, maio/agosto, 2018. 
Nietzsche, a genealogia, a história: Foucault, a genealogia, os corpos

foram produzidos. Os utilitaristas estariam na abertura da Genealogia da moral para manifestar isto: desconhecem uma história da moral cujas condições vitais não seja unicamente o valor da utilidade que firma o valor bom. Foucault, de todo modo, destitui o viés naturalista tanto dos utilitaristas quanto de Nietzsche, fornecendo uma interpretação mais "politizada" da Entstehungsheerd como lugar de enfrentamento, arena da luta. Ora, a fonte dos valores é vista como um espaço de investimento de forças que exige conhecer um resultado dessa origem. Este resultado é o corpo que se produz. Ele me parece o termos destacado da genealogia para Foucault.

\section{Consequências - $O$ corpo na história, vértice de luta: o lugar vazio da subjetividade em Foucault}

Ao descrever acima a relação da Herkunft com o corpo não expus, propositadamente, como este termo se destaca na ativação enfática que Foucault faz da genealogia. Se bem analisei, mesmo que o pensador passe pelo tema, o corpo se vê destituído da sua dimensão instintual e não se apresenta, como em Nietzsche, segundo uma análise da pluralidade de instintos. A implicação mais importante desta ausência não é a conclusão de que há um erro de leitura da genealogia de Nietzsche. É importante perguntar a Foucault: o corpo sem instinto, o que ele seria? Quais as consequências de assim pensá-lo? Retomemos a passagem em que Foucault o assinala:

Enfim, a proveniência pertence ao corpo (tient au corps) (...). O corpo - e tudo o que pertence ao corpo (tient au corps), a alimentação, o clima, o sol - é o lugar da Herkunft: sobre os corpos se encontra o estigma dos acontecimentos passados, do mesmo modo que dele nascem os desejos, os desfalecimentos e os erros; nele também se ligam e subitamente se exprimem, mas também nele se desligam, entram em luta, se apagam uns e outros e perseguem seu insuperável conflito. ${ }^{28}$

28 M. Foucault, 2001, pp. 1012-1013.

Cad. Nietzsche, Guarulhos/Porto Seguro, v.39, n.2, p. 125-160, maio/agosto, 2018. 
Ribeiro, C. E.

Nesta passagem, Foucault está se apoiando nos aforismos 42 de Aurora e no aforismo 200 de Além do bem e do mal e, a partir deles, propõe que o corpo é algo que resulta, que sobre ele se exerce um efeito e só assim ele se faria um corpo. É oportuna a citação destes trechos que leva em frente, mais uma vez, àquela urdidura intertextual com o que Foucault constrói um sentido geral.

No aforismo de Aurora em questão, o filósofo alemão propõe uma genealogia da vida contemplativa segundo os estados de força de uma época (nomeia seu aforismo de Herkunft der vita contemplativa). Diante de um estado de forças de uma "época crua" ou diante da decadência de tal estado, tipos sobressaem. Nietzsche concluirá, sob a perspectiva da decadência instintual, que "todos os produtos [de seu espírito] têm de refletir seu estado, o crescimento do temor e do cansaço, o decréscimo de sua estima pela ação e fruição" (M/A 42 KSA 3.49). A Herkunft da vida contemplativa é entendida, assim, como o nascimento de um juízo mau, um tipo de estima que origina a imaginação de novas superstições na qual vive "a mais antiga linhagem de naturezas contemplativas" (M/A 42 KSA 3.50). Em relação ao aforismo 200 de Além do bem e do mal, Foucault chega a citar, em alemão, uma passagem. São as primeiras linhas na qual Nietzsche afirma o corpo como herança, isto é, corpo que recebe uma marca e que marca a história para uma direção que denominaria, não sem problemas, de ancestralidade atual do corpo: "O homem de uma era de dissolução e de mestiçagem confusa, que leva no corpo uma herança de ascendência múltipla, isto é, impulsos e escalas de valor mais contraditórios, que lutam entre si e raramente se dão trégua (...)" (JGB/BM 200 KSA 5.120 grifo meu). Este aforismo do escrito de 1886, à semelhança do aforismo de Aurora citado, procura explicar na história natural da moral a formação de tipos culturais fracos e fortes. Entre os primeiros, coloca Agostinho e, entre os segundos, Alcibíades, César e Frederico II.

154 Cad. Nietzsche, Guarulhos/Porto Seguro, v.39, n.2, p. 125-160, maio/agosto, 2018. 
Nietzsche, a genealogia, a história: Foucault, a genealogia, os corpos

Estamos claramente lendo passagens que tratam de corpos que se vinculam a estados de forças determinados segundo o critério de ascendência ou decadência da vida, contudo, o acento de Foucault está não na configuração instintual que forjaram estes estados, estes tipos, mas no corpo que é resultado de. A dimensão intersticial do corpo é, assim, nitidamente indicada por Foucault na sequência desta citação: o corpo só se apreende porque, por ele, a história se faz como uma "superfície de acontecimentos". O corpo tem um modo duplo de operar como procedência: é tanto a história que chega a cada corpo (estigma de acontecimentos passados) como é aquele sobre o qual se faz a história (do corpo nascem os desejos, os erros; o corpo, ele lega algo como sua herança). ${ }^{29}$

É por este argumento que devemos nos remeter a uma caracterização inteiramente foucaultiana do que podemos chamar de procedência-corpo: por ele ser objeto de luta, o corpo é, paradoxalmente, um "volume em perpétuo arruinamento" (effritement). ${ }^{30}$ A metáfora não é fortuita. Ela exprime a genealogia como busca de um estado de forças que, em luta, produz uma soma vetorial provisória que logo se arruína. O corpo é um vértice da história, é uma encruzilhada que confere o valor de compreensão à genealogia. Existe para Foucault uma clara ambivalência corpo - história à medida que esta se realiza como a luta por aquele que, na verdade, é o resultado da luta. É conhecida a passagem na qual se explicita a ideia. Diz Foucault:

29 Embora não seja nossa posição, seria importante mencionar, a esse respeito, novamente as análises de Pizer. Foucault teria evitado conferir a Ursprung um papel positivo na práxis genealógica porque ele não quis ver a divisão entre origem e resultado, ou em outros termos, evitou pensar que entre origem e história há uma divisão ela própria crítica. A história tem uma Ursprung que a genealogia situa como a emersão de um tipo de vida. Mas, como se trata para Foucault de assumir uma prática descontinua, Pizer atribui ao francês uma negligência abusiva. Se é verdade que existe um acento nas dimensões da procedência e da emergência, não é verdade que Foucault é um genealogista descontinuísta apenas. E isto penso ficar esclarecido na primeira ênfase que vejo Foucault conferir à genealogia de Nietzsche (PIZER, op. cit, p. 476-478).

30 M. Foucault, 2001, p. 1011. 
Ribeiro, C. E.

A genealogia, como análise da proveniência, está, portanto, no ponto de articulação do corpo com a história. Ela deve mostrar o corpo inteiramente marcado de história e a história arruinando o corpo. ${ }^{31}$

Em outras palavras, a genealogia foucaultiana se forma na dimensão da subjetividade como espaço vazio no qual um corpo histórico efetivamente é conquistado. Uma história efetiva de corpos é permitida em Foucault porque ele ativou a genealogia de Nietzsche sob aquelas três ênfases, dando-lhes um importante caráter operacional. Ele o fez, sobretudo, à medida que são pelos corpos que as subjetividades são marcadas e afrontadas; que elas procedem como discursos e emergem como lugar de luta; que elas emergem como saberes enquanto revelam sua procedência estratégica de poderes. Estes corpos-subjetividades, entretanto, são pontos de emersão relativamente frágeis porque é preciso ver neles um estreitamento entre uma subjetividade que se faz emergir em um corpo que denuncia as múltiplas estratégias de lutas permanentes. Daí que, considerando o parti pris de Foucault, a práxis do Foucaultgenealogista é uma genealogia de corpos históricos ${ }^{32}$. Ela poderia ser definida como uma história crítica de corpos-acontecimentos que se pergunta: como se estreitaram o corpo e o poder na emersão de corpos-acontecimentos?

31 M. Foucault, 2001, p. 1011.

32 A expressão genealogia de corpos históricos merece uma explicação. É certo que, no pensamento de Foucault, uma genealogia de corpos é, de saída, uma genealogia de corpos históricos, o que faria da adjetivação um pleonasmo inútil, afinal a genealogia já é história. Mas emprego o histórico na expressão com legitimidade já que se trata de reiterar o que está sendo expresso em termos analíticos, a saber que a fabricação de corpos denuncia, na genealogia foucaultiana, relações estratégicas de subjetivação corporal e não um corpo em geral. O corpo psiquiatrizado e o corpo do enfermo, por exemplo, pertencem, por um lado, a uma genealogia comum de corpos no saber médico (como domínio de objetividade da doença), por outro, porém, se diferenciam como corpos históricos à medida que as estratégias do discurso psiquiátrico e o da medicina geral não coincidem. Pela genealogia, um corpo é histórico porque foi esquadrinhado de modo específico numa estratégica de um saber-poder. Basta refazermos a genealogia do corpo da clínica anatomopatológica e da clínica neurológica para sermos convencidos de suas historicidades como estratégicas específicas de controle. Assim, não se trata de corpos dados, mas emerge na condição de acontecimentos-corporais.

156 | Cad. Nietzsche, Guarulhos/Porto Seguro, v.39, n.2, p. 125-160, maio/agosto, 2018. 
Nietzsche, a genealogia, a história: Foucault, a genealogia, os corpos

Encontramos neste questionamento a originalidade mais profunda da genealogia de Foucault, o sujeito como função-sujeito, função vazia que o genealogia verá preenchida como diferentes corpos obtidos em luta. ${ }^{33}$ Para Foucault, como declara em $O$ poder psiquiátrico, há um ajuste e uma superposição disciplinar entre o poder e o corpo. Esta ligação entre o poder e o corpo é, no fundo, o modo pelo qual a genealogia foucaultiana ajusta o elemento-sujeito ao corpo, a forma segundo a qual o poder se estreita em direção a uma singularidade somática, o que corresponde precisamente à segunda e terceira ênfases que foi assinalada acima. Esta ligação é o que faz do corpo um corpo "subjetivado".

O conceito de função-sujeito, portanto, estrutura tal relação definindo a função exercida sobre um corpo que vem a ser individualizado num campo de forças. A função-sujeito, no fim das contas, substitui a configuração de impulsos e sua multiplicidade que, originalmente em Nietzsche, organizava uma genealogia da moral. Com Foucault, o próprio corpo seria, não uma forma de vida obtida em uma hierarquia de impulsos, mas o ajuste disciplinar promovido por uma individualização corporal que uma função-sujeito realiza.

Ao interpretar a genealogia, Foucault arma um jogo entre os textos de Nietzsche de maneira que haja entre eles uma articulação tal que toda uma releitura se organiza. Em suma, poderemos falar que Foucault dá um grande passo em falso ao "ler' a genealogia de Nietzsche. Mas é este mesmo passo que confere originalidade à genealogia foucaultiana. Esta luta, que é travada na história sobre os corpos, não reivindica nem uma tese vitalista sobre a história e até mesmo, em certa ocasião, o corpo será recusado explicitamente como sujeito libidinal por Foucault. ${ }^{\mathbf{3 4}}$ Em outras palavras, em havendo uma

33 Esta análise é feita a propósito da genealogia do poder psiquiátrico. Cf. M. Foucault, M., 2006, pp. 69-70.

34 Este tema indicia o sentido desta exigência em Foucault, proeminente na leitura da genealogia, em desligar o corpo de sua dimensão instintual. No interior do pensamento foucaultiano, este tema tem uma história: é a recusa da teoria do desejo no embate com a psicanálise, mas também 
Ribeiro, C. E.

clara dimensão pulsional e cosmológica no pensamento nietzschiano, Foucault, embora a reconheça e a tematize, tem interesse maior sempre nos mecanismos que "corporeificam" o sujeito na história. Na genealogia foucaultiana do poder, então, só os corpos é que fazem história porque são eles os efeitos efetivos de subjetividade de uma determinada luta histórica. Assim, a "distorção" que Foucault "comete" parece desfrutar da mais alta relevância para o futuro de seus trabalhos a partir destes anos 1970. Não coincidentemente, nesta mesma década, veremos nascer a relação genealogicamente perseguida por Foucault entre sujeito e poder. Assim, um corpo é aquilo pelo que se luta, uma espécie de termo final da própria luta na qual, sem dúvida, Foucault vê a genealogia do sujeito nascer como seu projeto filosófico. A cegueira de Ursprung, seu passo em falso: é preciso ver nisto tudo a origem da própria originalidade de Foucault como praticante da genealogia de Nietzsche.

o mote para realizar a genealogia do homem do desejo. Limito-me, a esse respeito, a recordar o embaraço no qual se meteu Foucault nos momentos finais de $A$ vontade de saber ao construir um dispositivo de sexualidade sem sexo, isto é, em que o corpo-desejante, o sexo-vida surgem tanto como estratégia do dispositivo quanto como seu elemento ideal, mas nunca como elemento irradiador da sexualidade. Ora, conhecemos o intervalo entre este tomo I e o tomo II da História da sexualidade. Intervalo que se dá porque Foucault percebeu, elaborando melhor a tarefa de desligar o corpo do desejo, ou de praticar uma genealogia da sexualidade sem um corpo instintual, a exigência maior de uma genealogia de como nos tornamos sujeitos desejantes exposta no capítulo Modificações (Cf. M. Foucault, 2003). Embora não possa analisar o tema, temos aí um percurso em que se constroem as linhas maiores do problema do desejo no pensamento de Foucault que melhor situaria sua cegueira em face da relação da genealogia com a Ursprung.

158 | Cad. Nietzsche, Guarulhos/Porto Seguro, v.39, n.2, p. 125-160, maio/agosto, 2018. 
Nietzsche, a genealogia, a história: Foucault, a genealogia, os corpos

\begin{abstract}
This article analyses the first four parts of Foucault's work Nietzsche, genealogy, history (1971), demonstrating that there are three elaborate emphases on genealogical procedure. They are determinants of the genealogical praxis of the French thinker. I propose two moments of analysis: a resumption and an evaluation of aspects of Foucault's "reading" of genealogy to develop the most important consequence from this parti pris: replacing the body as an instinct by the subject as a function, Foucault's genealogy finds its originality as genealogy of historical bodies
\end{abstract}

Keywords: genealogy - history - bodies - origin

\title{
Referências bibliográficas
}

FOUCAULT, M. História da Sexualidade I: a vontade de saber. Trad. Maria Thereza da Costa Albuquerque e J.A. Guilhon Albuquerque. 15ª ed. Rio de Janeiro: Graal, 1988.

. Dits et écrits II - 1976-1988. Paris: Gallimard, 2001.

. História da Sexualidade II; o uso dos prazeres. Trad. Maria Thereza da Costa Albuquerque. 10. ed. Graal: Rio de Janeiro, 2003.

. A Hermenêutica do Sujeito; curso dado no Collège de France, 1981-1982.

São Paulo: Martins Fontes, 2004.

. O poder psiquiátrico; curso dado no Collège de France (1973-1974).

São Paulo: Martins Fontes, 2006.

ITAPARICA, A. "Nietzsche e o sentido histórico". In: Cadernos Nietzsche, n.19, p.79-100, 2005.

NIETZSCHE, F. Nietzsche; Obras incompletas. Tradução de Rubens Rodrigues Torres Filho. São Paulo, Abril Cultural, 1974.

. Sämtliche Werke - Kritische Studienausgabe; edição organizada por Giorgio Colli e Mazzino Montinari. Berlim: Walter de Gruyter \& Co., 1967/1978. 15 vol. 
Ribeiro, C. E.

. Humain, trop humain; un livres pour esprits libres. textes et variantes établis par Giorgio Colli et Mazzino Montinari ; traduits de l'allemand par Robert Rovini. Paris: Gallimard, 1968.

. Fragments posthumes, début 1888-début janvier 1889; textes et variantes établis par Giorgio Colli et Mazzino Montinari ; traduits de l'allemand par Jean-Claude Hémery. Paris: Gallimard, 1977.

. Além do bem e do mal; Prelúdio de uma filosofia do futuro. Tradução, notas e posfácio de Paulo César de Souza. 2. ed. São Paulo: Companhia das Letras, 1992.

. Ecce Homo; Como alguém se torna o que é. Tradução, notas e posfácio de Paulo César de Souza. 2. ed. São Paulo: Companhia das Letras, 1995.

. Humano, demasiado humano. Tradução, notas e posfácio de Paulo César de Souza. São Paulo: Companhia das Letras, 2000a.

. Crepúsculo do Ídolos. Rio de Janeiro: Relume Dumará, 2000b.

- Genealogia da moral; uma polêmica. Tradução, notas e posfácio de Paulo César de Souza. São Paulo: Companhia das Letras, 2001.

. A gaia ciência. São Paulo: Companhia das letras, 2002. Tradução, notas e posfácio de Paulo César de Souza.

. Aurora: reflexões sobre os pensamentos morais. Tradução, notas e posfácio de Paulo César de Souza. São Paulo: Companhia das Letras, 2004.

. Sobre a utilidade e a desvantagem da história para a vida. Organização e tradução de André Itaparica. São Paulo: Hedra, 2017.

PIZER, J. The Use and Abuse of "Ursprung", On Foucault's Reading of Nietzsche. In: Nietzsche-Studien, Vol. 19, pp. 462-478, 1990.

Artigo recebido para publicação em 22/02/2018 Artigo aceito para publicação em 09/05/2018

$160 \mid$ Cad. Nietzsche, Guarulhos/Porto Seguro, v.39, n.2, p. 125-160, maio/agosto, 2018. 